\title{
An Interesting Case Report of a Giant Bladder Calculi in China
}

\author{
Chen Hui ${ }^{1,2 *}$, Huang Maping${ }^{1}$, Huang Tianhai ${ }^{1}$, Yang Xiaoyi ${ }^{1}$, Ni JJ' ${ }^{1}$ Li Qingqing ${ }^{1}$, Liu Qiuling ${ }^{1}$, Jiang \\ Chonghe $^{2}$ and Xie Keji ${ }^{3}$
}

${ }^{1}$ Department of Urology, Guangdong Provincial Work Injury Rehabilitation Hospital and Jinan University, Guangzhou, China ${ }^{2}$ Department of Urology, Qingyan City People's Hospital, Guangdong, China

${ }^{3}$ Department of Urology, Guangzhou First Municipal People's Hospital, Guangzhou, China

"Corresponding author: Chen Hui, Department of Urology, Guangdong Provincial Work Injury Rehabilitation Hospital and Jinan University, Guangzhou-510440, China, E-mail: doc.chenhui@163.com

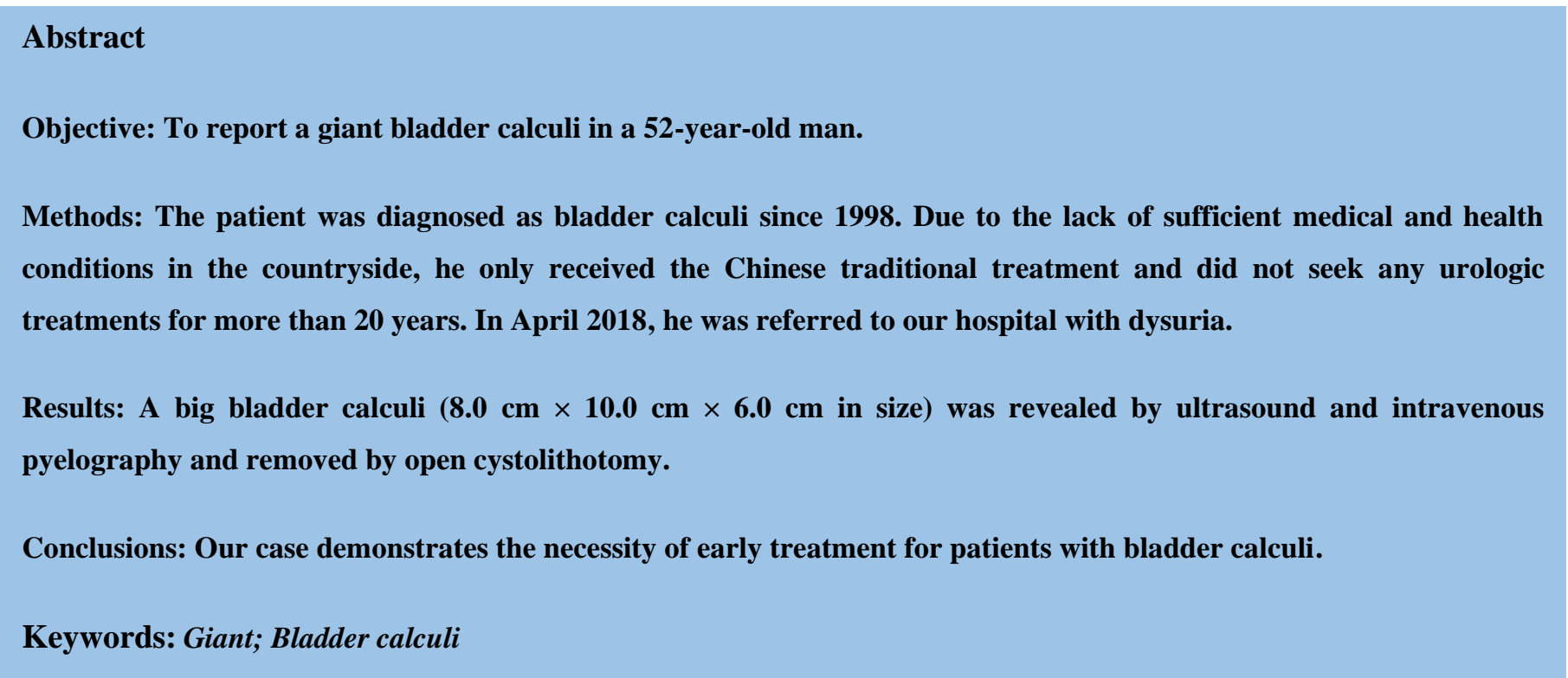

Received Date: October 17, 2018; Accepted Date: November 01, 2018; Published Date: November 08, 2018

\section{Introduction}

Bladder calculi is an old and rare disease which accounted for 5\% of all urinary calculi [1,2]. Now a days, based on technical improvements and a growing clinical expertise on minimally invasive treatment, a giant stone in bladder is a very rare condition in china during the past twenty years. In this report, we reported an uncommon case of large bladder calculi.

\section{Case Report}

In February 2018, a 52-year-old man was admitted to hospital due to a complaint of intermittent, painful voiding, terminal hematuria and interruption of the urinary stream. The patient's medical history revealed that some of these typical worsening discomforts had been observed twenty years prior to the present study. Due to the lack of sufficient medical and health conditions in the countryside, he only received the Chinese traditional treatment and did not seek any urologic treatments for more than 20 years.

Citation: Chen Hui, An Interesting Case Report of a Giant Bladder Calculi in China. J Clin Cases Rep 2(1): 12-16. DOI: https://doi.org/10.46619/joccr.2019.2-1030 
Systemic physical examination and rectal examination findings were normal. A complete urologic examination revealed a palpable solid oval-shaped mass, $8 \mathrm{~cm}$ in size, which originated from suprapubic region of the bladder. Both Color Doppler ultrasound of urinary system and intravenous pyelography (IVP) produced that a large, rounded calcified mass in the pelvis (Figure 1).

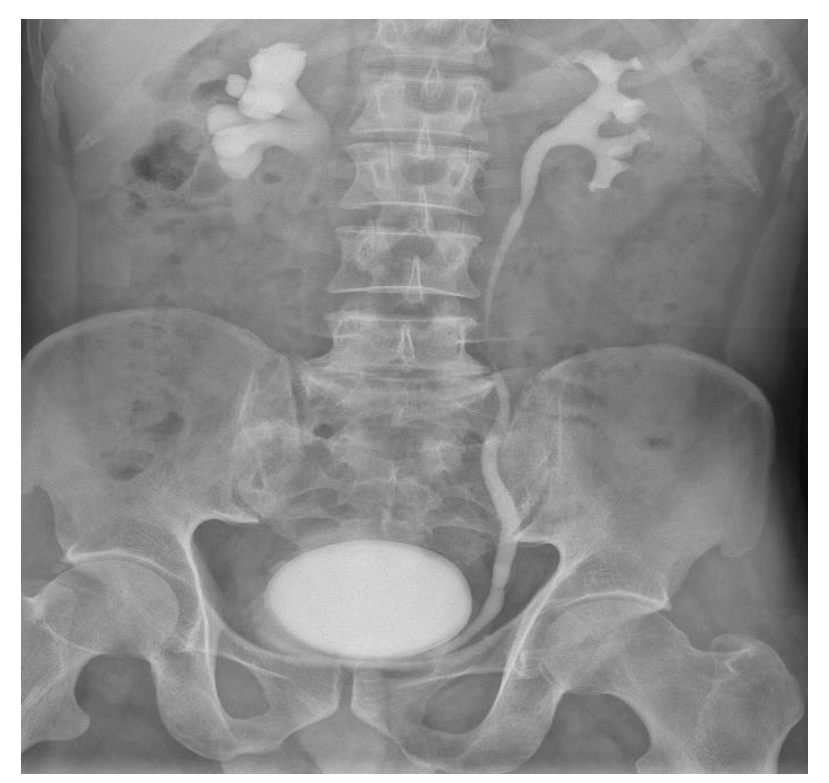

Figure 1: Showing a giant bladder calculi in the pelvic area.

Undoubtedly, it is difficult for endoscopic techniques to remove such a giant bladder calculi completely. Hence, open cystolithotomy was performed (Figure 2).

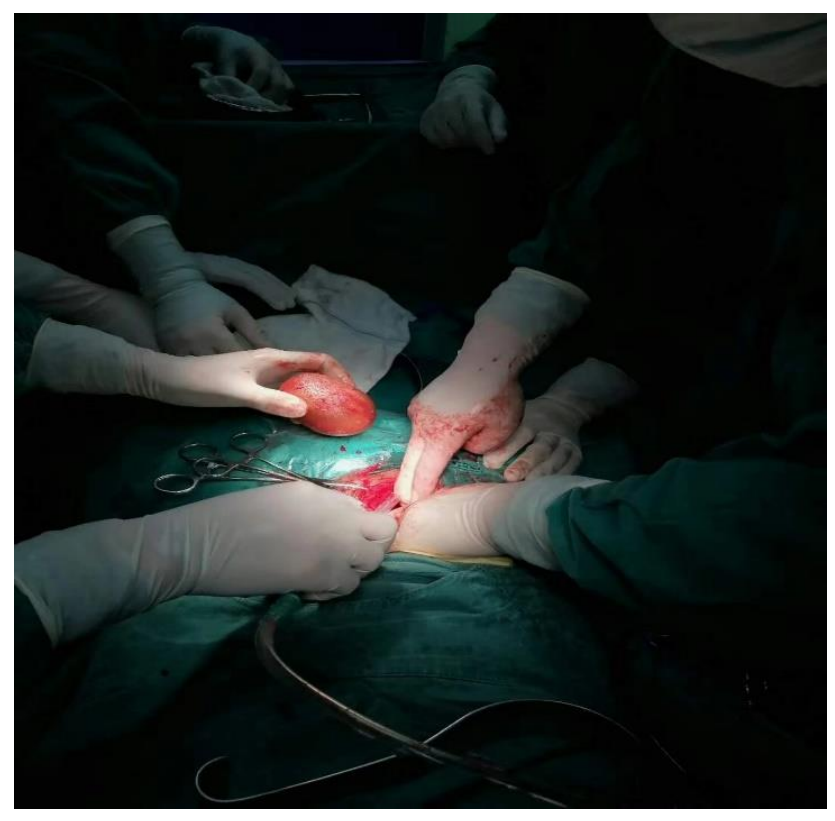

Figure 2: The giant bladder calculi was removed from bladder.

More interestingly, although the bladder calculi size was relatively huge, it was removed easily and completely without adhesion to the bladder wall. The extirpated bladder calculi measured $8.0 \mathrm{~cm} \times 10.0 \mathrm{~cm} \times 6.0 \mathrm{~cm}$, and weighed $293.1 \mathrm{~g}$ (Figure 
3 and Figure 4). The postoperative 3 months follow-up was uneventful and without any urologic complaint. The calculus was analyzed and found to be composed of cystine.

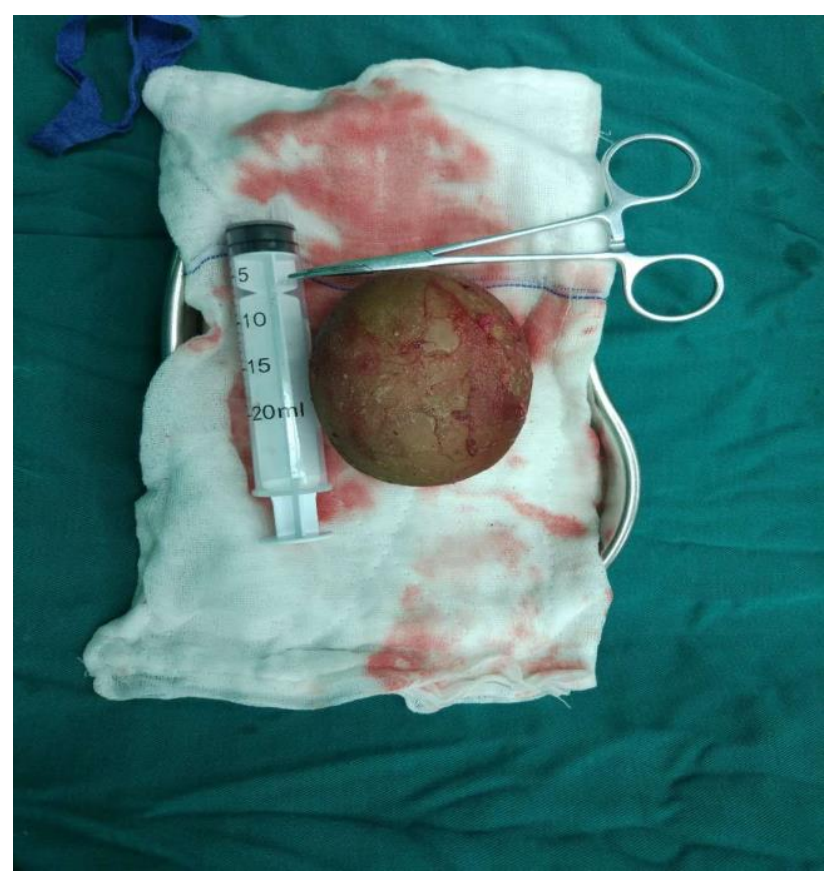

Figure 3: An intraoperative photograph showing the bladder calculi.

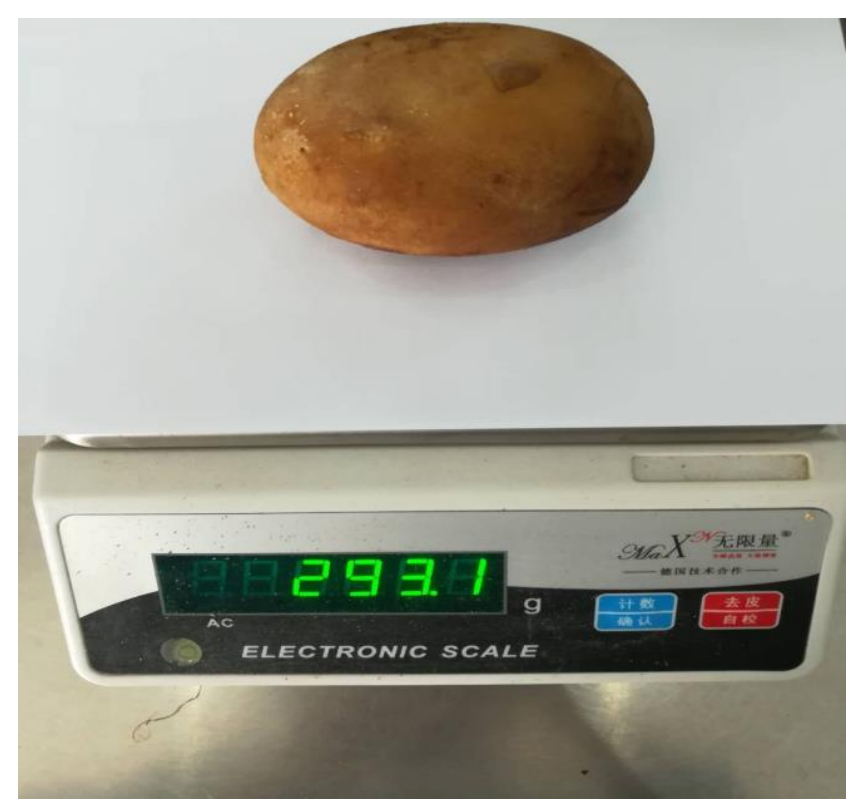

Figure 4: The extirpated calculi weighed $293.1 \mathrm{~g}$.

\section{Discussion}

It is well recognized that bladder stone usually result from bladder outlet obstruction, neurogenic voiding dysfunction, or recurrent urinary tract infection [3]. Bladder calculi are usually solitary but may develop in multiple stones in the presence of urinary stasis [4]. With the rapid development of China's economy and health care, bladder stones weighing more than $100 \mathrm{~g}$ are extremely rare. Undoubtedly, the present case report was more interesting. Firstly, a review of the literature shows that 
http://www.tridhascholars.org | January-2019

similar studies of giant bladder stone in china are scanty. Secondary, the extremely large bladder calculi occupied most of the bladder and pressing on the orifices of the ureters, leading to the presence of hydronephrosis. Thirdly, the most important point was that we found no obstructed bladder outlet during the operation. The reasons we analyzed were that the bladder stone formed after an upper urinary tract calculus descended into the bladder a long time ago.

Now a days, it was well known that open approach has been progressively replaced by newer techniques aimed to be less invasive [5]. However, irrespective of a large number of alternative surgical procedures available today, we still choose open cystolithotomy as treatment choices for this case because it ensured wide vision of the surgical field to remove such a larger bladder calculi more rapidly and entirely. Fortunately, the bladder calculi were smooth and not adherent to the bladder wall which help avoid hematuria, bladder perforations and mucosal injuries risk.

Bladder calculi is associated with chronic irritation and inflammation which play a direct role in the development of bladder cancer [6,7]. In 2008, Farouk K and his colleague [8] reported a 65-year-old man with bladder leiomyoma and bladder stone. In 2013, another study [9] even reported that bladder calculi was found up to 71(3.4\%) cases in 2,086 patients with bladder cancer between 2001 and 2009. Fortunately, in this case, the interior of the patient bladder was normal and no neoplasm was visible to the naked eyes after the stone was removed.

\section{Conclusion}

This case study reported satisfactory results for a giant stone in 2-year-old male patient. However, bladder stone should be taken into consideration when patients develop lower urinary tract symptoms or other signs occur, such as intermittent, painful voiding, terminal hematuria recurrent urinary tract infection and interruption of the urinary stream.

\section{Acknowledgement}

This study was supported by Medical Scientific Research Foundation of Guangdong Province, China (grant number A2013477, A2018124). There is no a financial or other conflict of interest between your work and that of the authors.

\section{References}

1. Sorokin I, Mamoulakis C, Miyazawa K, et al. (2017) Epidemiology of stone disease across the world. World Journal of Urology 35(9): 1301-1320.

2. Schwartz BF, Stoller ML (2000). The vesical calculus. The Urologic Clinics of North America 27: 333-346.

3. Türk C, Petř́k A, Sarica K, et al. (2016) EAU Guidelines on interventional treatment for urolithiasis. European Urology 69(3):475-482.

4. Torricelli FC, Chueh SJ, Shen S, et al. (2017) Multiple uric acid bladder stones: Clinical presentation and endoscopic Management. Journal of Endourology Case Reports 3(1): 21-23.

5. Cicione A, DE Nunzio C, Manno S, et al. (2018) Bladder stone management: an update. Minerva Urologica e Nefrologica $70(1): 53-65$.

6. Chamie K, Litwin MS, Bassett JC, et al. (2013) Recurrence of high-risk bladder cancer: a population-based analysis. Cancer 119(17): 3219-3227.

7. Nesi G, Nobili S, Cai T, et al. (2015) Chronic inflammation in urothelial bladder cancer. Virchows Archiv: An International Journal of Pathology 467(6): 623-633. 
http://www.tridhascholars.org | January-2019

8. Farouk K, Gondal M, Ahmad A, et al. (2008) Leiomyoma of the urinary bladder with bladder stone. Journal of College of Physicians and Surgeons - Pakistan 18(9): 592-594.

9. Shiu-Dong C, Ming-Chieh T, Lin CC, et al. (2013) A case-control study on the association between bladder cancer and prior bladder calculus. BMC Cancer 13: 117. 